\title{
Clinical and Radiographic Evaluation of Young Permanent Teeth Capped with Biodentine
}

\author{
Karine Takahashi ${ }^{1 *}$, Heitor Ceolin Araujo ${ }^{2}$, Henrique Augusto Banci ${ }^{1}$, Daniela Nardi Mancuso ${ }^{2}$ and Eloi Dezan \\ Junior ${ }^{3}$
}

${ }^{1}$ Department of Pediatric Dentistry, West Sao Paulo University, Brazil

${ }^{2}$ Department of Pediatric Dentistry, University of Sao Paulo State, Brazil

${ }^{3}$ Department of Endodontics, University of Sao Paulo State, Brazil

*Corresponding author: Karine Takahashi, Department of Pediatric Dentistry, Profesor at West Sao Paulo University, Francisco Scardazzi Street number 350, Sao Judas Park, Zip code 19023190, Presidente Prudente city, Sao Paulo State, Brazil

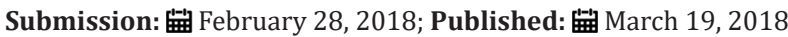

\begin{abstract}
Permanent molars suffer more occurence of tooth decay as they easy accumulate biofilm in pits and fissures. Difficulties in diagnosing and managing lesions in these teeth are a problem for the clinicians, specially concerned to pulpal vitality preservation. Pulpotomy is a conservative approach in treatment of pulp tissues, indicated mainly for open apex teeth. The objective of this study was to evaluate clinically and radiographically after 3 and 6 months young permanent teeth submitted to pulpotomy and direct pulp capping using Biodentine. After 3 months of the intervention, the clinical and radiographic evaluation yielded a $100 \%$ success rate in the patient's response, since the thermal and percussion tests were positive, and no periapical lesion was observed on the radiograph. At 6 months, the value of $p<0.05$, indicating that there is a statistical difference between the nominal qualitative variables (Absent and Present), of the clinical and radiographic tables evaluated (postoperative pain, periapical lesion and pulp necrosis). Based in the radiographic and clinical results, Biodentine presented significal potential as a filling material in pulpotomies in young permanent teeth.
\end{abstract}

Keywords: Endodontics; Pulpotomy; Dentition; Permanent

\section{Introduction}

Tooth decay even though dentistry advances is still considered a public health problem. Permanent molars suffer more occurence of tooth decay as they easy accumulate biofilm in pits and fissures. 12-year-old Brazilian children present an average of 2,07 teeth with tooth decay experience. Difficulties in diagnosing and managing lesions in these teeth are a problem for the clinicians, specially concerned to pulpal vitality preservation [1]. Pulpotomy is a conservative approach in treatment of pulp tissues, indicated mainly for open apex teeth [2]. According to Mc Call [3], it can be performed in cases of small exposure, normal bleeding, and good coloring of the remaining pulp.

In these cases, after the removal of the damaged pulp tissue, a liner material must be used to promote healing and proper repair. The sings of sucess after this intervention are the normal response to termal sentitivity tests and the absence of pain, besides the radiographic evidence of hard tissue formation and the continuation of root formation [4]. The most used materials in pulpotomy are the mineral aggregated trioxide (MTA), calcium hydroxide and calcim silicate. Since 1936, calcium hydroxide has been considered the gold standard in pulp therapies, due to its biological compability as a delay dressing, and it has shown good results in direct and indirect pulp capping [5]. However calcium hydroxide has shown some failures, as low adhesion to dentin, reabsorption and mechanical instability. In addition to that the material doesn't prevent microleackage overtime allowing the entry of microorganisms [6].

The calcium hydroxide is the most used material in these case [7]. Holland et al. [8], studies point that in $90 \%$ of the treated teeth show the formation of a hard tissue barrier. Oliveira [9] performed pulpotomy with calcium hydroxide in active powder, and for better verification of the occurrence or absence of the formation of the hard tissue bridge, it was made the removal of all restoration and the cinical examination straight from the mouth of the canals, finding a rate of $100 \%$ of sucesso $n$ the examined teeth. Souza [8] confronted the histological and radiographic results of sucess of the pulpotomies and verifed a big correlation between the results found, when dealing with the formation of the hard tissue.

Another material recently launched is the Biodentine $₫$ (Septodont, Saint Maur des Fossés, France), which is a calcium silicate based cement, with similar mechanical properties as dentin, being used as a substitute of dentin on the crown [10-16]. In vitro studies show that in contact with the vital pulp cells it has a positive 
effect stimulating the formation of tertiary dentin $[10,11,17]$. Some authors affirm that this material has superior properties when compared to MTA, mainly in its clinical use [18].

The powder is composed of tricalcium silicate, dicalcium silicate, calcium oxide, iron oxide, calcium carbonate and, as a radiopacifier, zirconium oxide, insofar the liquid is composed of water, calcium chloride and polycarboxylate, a water reducting agent with the surfactant effect [19]. It has indications both in restorative dentistry and endodontics, due to the fact that it can be used in temporary restorations in enamel and definitive ones in dentin, deep cavity lining, cervical and root restorations, direct pulp capping and pulpotomy, sealing of furcation perforation, internal and external perforating resorption, apicification and retrograde obturation in parendodontic surgeries $[20,21]$. It is a cement that increases the biomineralization and cell proliferation [22].

Biodentine is commercially sold in individual capsules composed of tricalcium silicate, calcium carbonate and zirconium oxide, which are mixed with a liquid containing water, calcium chloride to accelerate the setting and modifed polycarboxylate as a plasticizing agent. It has good work conditions due to its good viscosity and the short setting time, of about 12 minutes [23]. Besides that, it also has better physico-chemical properties when compared to MTA [24-26].

Studies in the literature compare the efficiency of Biodentine and MTA when used directly on the pulp tissue aiming the formation of a hard tissue barrier [27]. There are difficulties in diagnosis and menagement of tooth decay with pulp involvement in permanent teeth, despite being common in day-to-day clinical practice. Clinical studies evaluating the success of therapies should be encouraged, especially by testing new materials, such as the proposed use of Biodentine.

Pulp therapy in permanent teeth with vitality refers to the treatment that aims to preserve and maintain pulp tissue compromised but not totally destroyed by tooth cavity, trauma or restorative procedures in a state of health. The objective is to stimulate the formation of restorative dentin and maintain the tooth in functional state [5].

The preservation of pulp tissue is a clinical challenge in restorative dentistry, especially when dealing with the management of immature permanent teeth. After the removal of the damaged pulp tissue, materials that allow tissue repair should be used. Indicators of success in these cases would be positive response in pulp tests and absence of pain, radiographic confirmation of the formation of hard tissue bridge and continuation of root formation In addition, there should be no clinical or radiographic evidence of internal resorption and apical periodontitis [1].

\section{Objective}

The objective of this study was to evaluate clinically and radiographically after 3 and 6 months young permanent teeth submitted to pulpotomy and direct pulp capping using Biodentine.

\section{Material and Methods}

The research was initiated and executed after the approval of the Research Ethics Committee of The University of Western São Paulo (UNOESTE) (Protocol 3464). The subjects of the research only participated after the signing of the Informed Consent Form (TCLE) filled out by the Parents or the Children's Responsibility. The study was conducted at the Pediatric Dentistry Clinic of the Faculty of Dentistry of Presidente Prudente (FOPP) of the University of Western São Paulo (UNOESTE) in 25 children aged from 8 to 14 years old.

\section{Inclusion criteria}

There were included in this study children who:

a) Children who accepted to participate in the research;

b) Children whose parents agreed to sign the Informed Consent Form;

c) The ones who presented the first permanent molars with lesions of caries compatible with ICDAS 5 or 6 and immature apexes;

d) The ones who presented the first permanent molars without painful symptomatology, or caused pain, and without radiographic changes indicating of periapical lesion or resorptions;

e) Teeth with restorative treatment possibility;

f) Children with a behavior that would allow the treatment to be performed.

The indication of pulpotomy was observed after the removal of the carious tissue, in which there was accidental exposure of the pulp to young permanent teeth. Clinical evaluations were performed to verify pulp vitality, such as thermal tests and initial radiography to verify the extent of the carious lesion and the absence of periapical lesion.

For the pulpotomy technique, infiltrative terminal anesthesia was performed for upper teeth and inferior alveolar nerve block for lower teeth. After the absolute isolation, the ceiling was removed from the pulp chamber and the cut of the coronary pulp with endodontic curettes with abundant irrigation with saline solution. When the pulp bleeding had ceased in about 3 minutes, it was placed with Otosporin sterile cotton ball for 5 minutes, and finally the material studied, Biodentine (Septodont ${ }^{\circledR}$, France), according to the manufacturer's recommendations.

After 3 and 6 months of the technique, the patients were remarked for evaluation, in which the absence of pain, absence of pulp necrosis and periapical lesion were evaluated. For clinical evaluation, thermal and percussion tests were performed, as well as periapical radiographs with radiographic positioner for standardization, in which there was no lesion and continuity of root formation 
The teeth were evaluated according to the criteria of Cooke \& Rowboyham (1956) that evaluate the absence of symptoms, normal apical development, radiographic evidence of a dentin bridge, a hard blade formation, normal alveolar bone and normal pulpal response to vitality tests. In addition, the teeth should not have dental mobility, percussion sensitivity and internal resorption (Law, 1956).

\section{Statistical Analysis}

For the statistical analysis the chi-square test was used, with the SigmaPlot 12.0 Software.

\section{Results}

After 3 months of the intervention, the clinical and radiographic evaluation yielded a $100 \%$ success rate in the patient's response, since the thermal and percussion tests were positive, and no periapical lesion was observed on the radiograph.

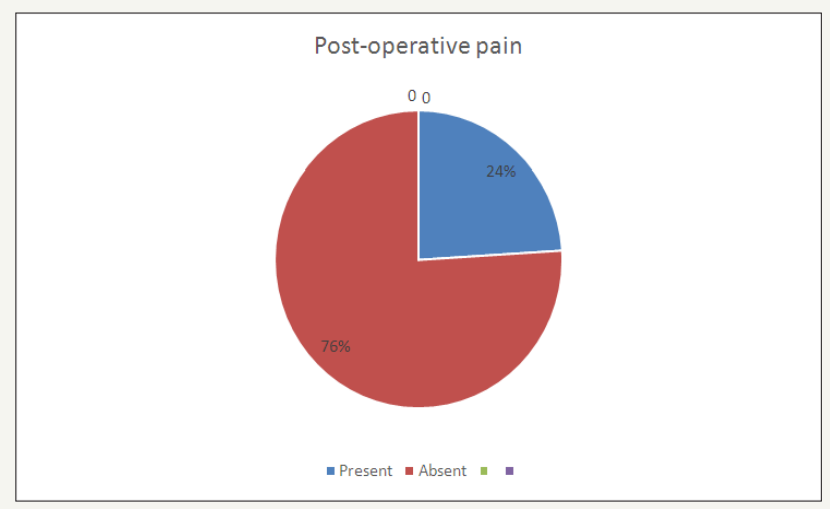

Figure 1: Evaluation of presence or absence of postoperative pain in young first permanent molars after pulpotomy biodentine application.

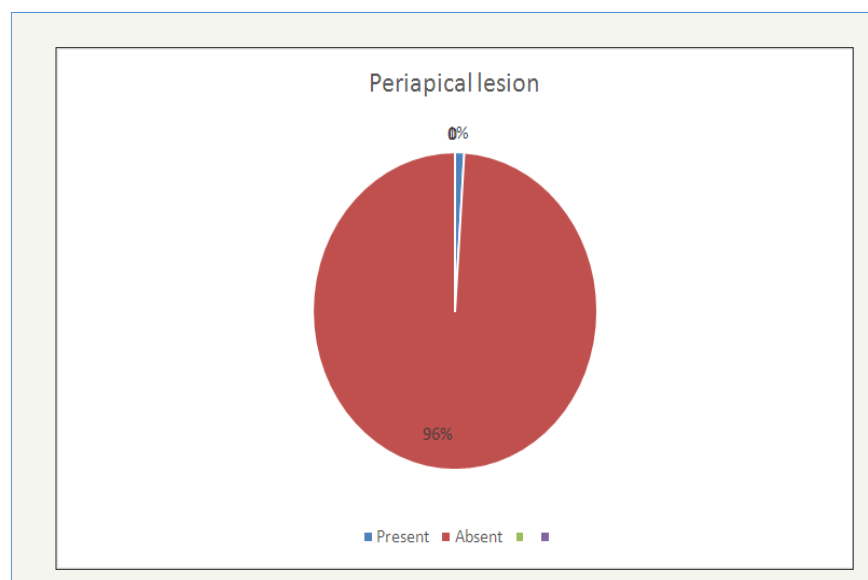

Figure 2 : Evaluation of presence or absence of periapical lesion in young first permanent molars after pulpotomy biodentine application.

At 6 months, the value of $\mathrm{p}<0.05$, indicating that there is a statistical difference between the nominal qualitative variables (Absent and Present), of the clinical and radiographic tables evaluated (postoperative pain, periapical lesion and pulp necrosis) (Figure 1-3).

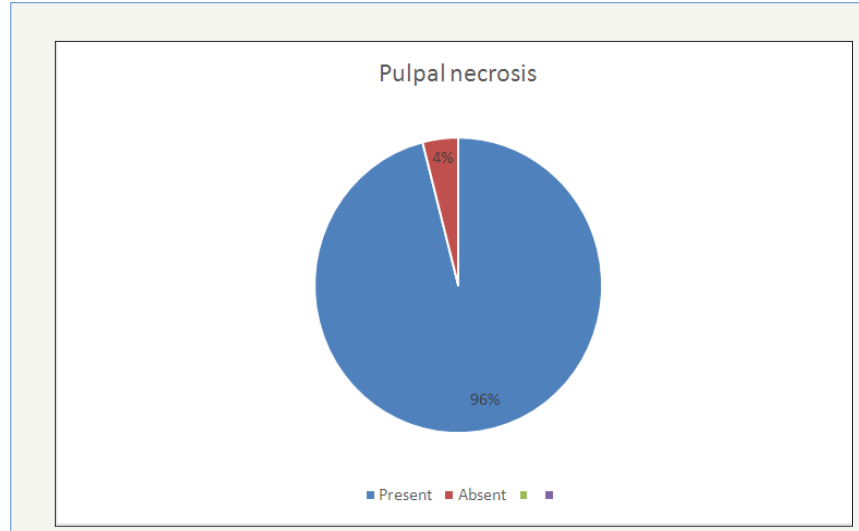

Figure 3 : Evaluation of presence or absence of pulpal necrosis in young first permanent molars after pulpotomy biodentine application.

\section{Discussion}

Pulpotomy is another type of treatment in which Biodentine can be used favorable mainly in Pediatric Dentistry. In these cases, the regeneration of hard tissue occurred and it did not lead to middle or high inflammatory pulpal response. Besides, it also showed high sealing ability and necrosis risk.

Materials based in calcium silicate base have gained popularity in recent years due to the similarity to MTA, specially Biodentine (Septodont, 2009). It was developed as a dentin repository and has lots of indications in endodontic repair and as pulpal capping material in restorative dentistry.

Biocompatibility is an important proper when choosing a pulpal capping material, or in radicular perforations and retrograde obturation. Studies demonstrated calcium and silicate tags formation in the material interface and high diffusion of calcium ions. Studies show significal increase of TGF-B1 pulpal cells secretion. Biodentine affects positively the prepare when in direct contact with pulpal tissue, favoring proliferation, migration and adhesion of repair pulp cells as a characteristic of biocompatibility [28].

A pioneer study in inflammatory response of human cells showed that Biodentine has biocompatibility, inflammatory response and similar odontoblastic differentiation when compared to MTA [29]. Although one in vitro study demonstrated that Biodentine has fewer pulpal cell recruitment [30].

Similar results were found in Biodentine and MTA in relation to citotoxicity and citocines expression [31]. Biodentine in vitro studies shows better release of calcium ions [32]. Also Biodentine is bioactive and biocompatible, for this reason, being a material that induces to odontoblasts differentiation [33].

Hard tissue bridge induced by Biodentine shows good location and a pattern of development, being favorable than other materials such as calcium hydroxide [27,34]. Besides that, material, even when applied in single session, brings to continuation of root development and apical closure [35]. Studies showed high percentage of hard 
tissue bridge after its application [27]. In another one, it failed to detect radiographic hard tissue bridges after Biodentine utilization [18].

There are few studies in Literature describing the use of the material, mainly in relation to clinical aspects. All studies confirm that the material proves to be favorable and promising as an alternative in clinical applications [28].

In a clinical and radiographic evaluation at 6 and 12 months after Biodentine use in direct pulp capping in young permanent teeth, Biodentine showed success rates of $100 \%$ in 7 to 9 -uear-old children [36]. Other authors also found high success rates in clinical evaluations with use of this material in pulp capping [37].

Biodentine has color stability comparing to MTA, and it is indicated in pulpal procedures in young permanent teeth, once it releases calcium hydroxide, that leads to hard tissue formation [38].

It also demonstrates benefits in relation to MTA, as reduced operative time, higher compressive forces and sealing ability. It has bioactives properties and regenerative capacity of hard tissues. Besides, one single advantage of these material seems to be maintenance of pulpal vitality until radicular formation and apical closure [22].

There is no reliable and objective method for clinical evaluation of pulpal inflammation extension and pathological condition, as its detection is based on subjective description of symptoms, in pulpar sensibility tests and radiographic exams [39].

\section{Conclusion}

Based in the radiographic and clinical results, Biodentine presented significal potential as a filling material in pulpotomies in young permanent teeth.

\section{References}

1. Villat C, Grosgogeat B, Seux D, Farge P (2013) Conservative approach of symptomatic carious immature permanente tooth using a tricalcium silicate cement (Biodentine): a case report. Restor Dent Endod 38(4): 258-262.

2. Messing JJ, Stock CJR (1988) Tratamiento del paciente con urgencia. In: Atlas color de endodoncia. Madrid: Ediciones Avances Cap 7: 104.

3. McCall JO (1937) Pulpotomy: its place in modern dentistry. J Can Dent Assoc 3: 177

4. European Society of Endodontology (2006) Quality guidelines for endodontic treatments: consensus report of the European Society of Endodontology. Int Endod J 39(12): 921-930.

5. Grewal N, Salhan R, Kaur N, Patel HB (2017) Comparative evaluation of calcium silicate-based dentin substitute (Biodentine) and calcium Hydroxide (Pulpdent) in the formation of reactive dentin bridge in regenerative pulpotomy of vital primary teeth: triple blind, randomized clinical trial. Contemp Clin Dent 7(4): 457-463.

6. Dammaschke T (2012) A new bioactive cement for direct pulp capping. Int Dent Australasian 7(2): 52-58.

7. Paranjipe A, Zhang H, Johnson JD (2010) Effects of mineral trioxide aggregate on human dental pulp cells after pulp-capping procedures. Endod 36(6): 1042-1047.
8. Souza V, Holland R, Hysatugu R (1971) Evaluation of X-ray examination in the diagnosis of pulp response to conservation treatment. NYJPD 41(6): 207-213.

9. Oliveira MAF (1993) Avaliação clínica e radiográfica de uma técnica de pulpotomia realizada com e sem isolamento absoluto. Pelotas, p. 119.

10. Laurent P, Camps J, About I (2012) Biodentine (TM) induces TGF- $\beta 1$ release from human pulp cells and early dental pulp mineralization. Int Endod J 45(5): 439-448.

11. Zanini M, Sautier JM, Berdal A, Simon S (2012) Biodentine induces immortalized murine pulp cell differentiation into odontoblast-like cells and stimulates biomineralization. J Endod 38(9): 1220-1226.

12. Koubi G, Colon P, Franquin JC, Hartmann A, Richard G, et al. (2013) Clinical evaluation of the performance and safety of a new dentine substitute, Biodentine, in the restoration of posterior teeth: a prospective study. Clin Oral Investig 17(1): 243-249.

13. Koubi S, Elmerini H, Koubi G, Tassery H, Camps J (2012) Quantitative evaluation by glucose diffusion of microleakage in aged calcium silicatebased open-sandwich restorations. Int J Dent 2012: 105863.

14. Raskin A, Eschrich G, Dejou J, About I (2012) In vitro microleakage of Biodentine as a dentin substitute compared to Fuji II LC in cervical lining restorations. J Adhes Dent 14(6): 535-542.

15. Laurent P, Camps J, De Meo M, Dejou J, About I (2008) Induction of specific cell responses to a $\mathrm{Ca}_{3} \mathrm{SiO}_{5}$-based posterior restorative material. Dent Mater 24(11): 1486-1494.

16. Tran XV, Gorin C, Willig C, Baroukh B, Pellat B, et al. (2012) Effect of a calcium-silicate-based restorative cement on pulp repair. J Dent Res 91(12): 1166-1171.

17. Peng W, Liu W, Zhai W, Jiang L, Li L, et al. (2011) Effect of tricalcium silicate on the proliferation and odontogenic differentiation of human dental pulp cells. J Endod 37(9): 1260-1266.

18. De Rossi A, Silva LA, Gatón-Hernández P, Sousa-Neto MD, Nelson-Filho $P$, et al. (2014) Comparison of pulpal responses to pulpotomy and pulp capping with Biodentine and MTA in dogs. J Endod 40(9): 1362-1369.

19. Fonseca TS (2014) Resposta tecidual induzida por Biodentine ${ }^{\mathrm{TM}} \mathrm{e}$ MTA Branco em subcutâneo de ratos. Repositório Institucional UNESP.

20. Soundappan S, Sundaramurthy JL, Raghu S, Natanasabapathy V (2014) Biodentine versus MTA versus intermediate restorative material for retrograde root end filling an in vitro study. J Dent (Tehran) 11(2): 143149.

21. Sanghavi T, Shah N, Shah RR (2013) Comparative analysis of sealing ability of biodentin and calcium phosphate cement against MTA as a furcal perforation repair material an in vitro study. Natl J Integr Res Med 4(3): 56-60.

22. Ashraf H, Rahmati A, Amini N (2017) Vital pulp therapy with calcium silicate cements: report of two cases. Iranian Endod J 12(1): 112-115.

23. Vidal K, Martin G, Lozano O, Salas M, Trigueros J, et al. (2016) Apical closure in apexification: a review and case report of apexification treatment of an immature permanent tooth with biodentine. J Endod 42(5): 730-734.

24. Singh H, Kaur M, Markan S, Kapoor P (2014) Biodentine: a promising dentin substitute. J Interdiscipl Med Dent Sci 2(5): 1000140-1000145.

25. Rajasekharan S, Martens LC (2014) Biodentine ${ }^{\mathrm{TM}}$ material characteristics and clinical applications: a review of the literature. Eur Arch Paediatr Dent 15(3): 147-158.

26. Camilleri J, Sorrentino F, Damidot D (2013) Investigation of the hydration and bioactivity of radiopacified tricalcium silicate cement, Biodentine and MTA Angelus. Dent Mat 29(5): 580-593. 
27. Nowicka A, Lipski M, Parafiniuk M, Tutak KS, Lichota D, et al. (2013) Response of human dental pulp capped with biodentine and MTA. J Endod 39(6): 743-747.

28. Malkondu O, Kazandag MK, Kazazoglu E (2014) A review on Biodentine, a contemporary dentine replacement and repair material. BioMed Res Int 2014: 1-8.

29. Chang SW, Lee SY, Ann HJ, Kum KY, Kim EC (2014) Effects of calcium silicate endodontic cements on biocompatibility and mineralization inducing potentials in human dental pulp cells. J Endod 40(8): 11941200.

30. Giraud T, Rufas P, Chmilewsky F, Rombouts C, Dejou J, et al. (2017) Complement activation by pulp capping materials plays a significant role in both inflammatory and pulp stem cells recruitment. J Endod 43(7): 1104-1110.

31. Corral Nuñez CM, Bosomworth HJ, Field C, Whitworth JM, Valentine RA (2014) Biodentine and MTA induce similar cellular responses in fibroblast cell line. J Endod 40(3): 406-411.

32. Camilleri J, Laurent P, About I (2016) Hydration of Biodentine, Theracal LC and a phototype tricalcium silicate -based dentin replacement material after pulp capping in entire tooth cultures. J Endod 40(11): 1846-1854.
33. Luo Z, Kohli M, Yu Q, Kim S, Qu T, et al. (2014) Biodentine induces human dental pulp stem cell differentition trough mitogen-activated protein kinase and calcium-calmodulin dependente portein kinase II pathways. J Endod 40(7): 937-942.

34. Tziafa C, Koumpia EK, Papadimitriou S, Tziafas D (2014) Dentinogenic responses after direct pulp capping of miniature swine teeth with biodentine. J Endod 40(12): 1967-1971.

35. Aldakak MMN, Capar ID, Rekab MS, Abboud S (2016) Single visit pulp revascularization of a nonvital immature permanente tooth using biodentine. Iranian Endod J 11(3): 246-249.

36. Katge FA, Patil DP (2017) Comparative analysis of 2 calcium silicatebased cements (Biodentine and MTA) as direct pulp capping agente in young permanente molars: a split mouth study. J Endod 43(4): 507-513.

37. Strassler HE, Levin R (2011) Biodentine tricalcium-silicate cement. Inside Dent 7(10): 2-4.

38. Camilleri J (2015) Staining potential of neo MTA Plus, MTA plus and Biodentine used for pulpotomy procedures. J Endod 41(7): 1139-1145.

39. Hashem D, Mannoci F, Patel S, Manoharan A, Brown JE, et al. (2015) Clinical and radiographic assesment of the efficacy of calcium silicate indirect pulp capping: a randomized controlled clinical trial. J Dent Res 94(4): 562-568.

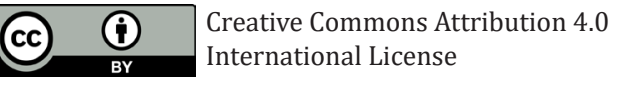

For possible submissions Click Here

\section{Submit Article}

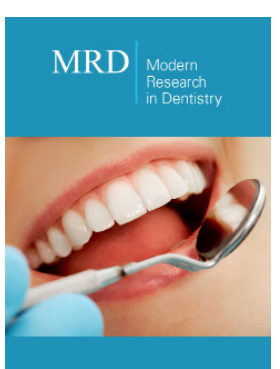

\section{Modern Research in Dentistry}

Benefits of Publishing with us

- High-level peer review and editorial services

- Freely accessible online immediately upon publication

- Authors retain the copyright to their work

- Licensing it under a Creative Commons license

- Visibility through different online platforms 